\section{NOTES ON THREE PERSONS STRUCK BY LIGHTNING.}

ONE DEATH; TWO RECOVERIES.

\section{By DANIEL MACKLTTOSH, M.D.}

ON the evening of Friday, the 20th May last, I was sum. moned to go with all speed, as the messenger would have it, " to see a number of persons who were all killed, or nearly so, by a stroke of lightning." On my way to the place of accident I could already see a crowd of people near to a huge stack of straw, to which latter my attention was attracted by the fact that it was enveloped in flames. One person after another told me that a man and two boys had resorted thitherwards for shelter; that the three were struck by the electric fluid; that the same flash which struck them set the stack on fire; and that a labouring man, who also was running for shelter to the same resort, seeing the stack on fire, and finding that it ignited from the very spot where his fated fellow-labourers were in shelter, naturally enough hastened to their rescue, and suc ceeded in removing them to a proper distance from the de. vouring element. Here I found my patients, about twenty minutes after the occurrence, to make my own deductions and conclusions.

CASE 1.-_Edward W- aged ten, was now able to walk about, although he had twenty minutes previously to be carried from the source of danger. Un questioning this little boy as to what he had seen and felt, he told me that he saw the stack take fire, and that he immediately said to his father, who sat beside him-" Father, let us run ; the stack is on fire." But his father not answering him, he tried to move away himself, but found he could not, and he then cried out for help. (This statement was corroborated by the man who carried him away.) On asking him why he could not run away, seeing that he was able to speak, his reply was, "I felt so dizzy all over, and my legs would not carry me." He pointed to the lower part of the abdomen, and said, "It is here it hurts me." On undoing his clothes, a peculiar sulphuro-singed odour was perceptible, and I could at once see several irregular but distinct red sureaks, of about a finger's breadth, running obliquely downwards and inwards on either side of the chest to the middle line in front of the abdomen, whence, being met, they descended over the linea alba, penis, and scrotum, and were lost on the perineum; penis and scrotum being of a brighter tinge of red than the course of streaks throughout, owing, no doubt, to the higher degree of vascularity of those parts. Neither hair nor clothes were singed; metallic buttons presented no appearance of fusion. He rapidly recovered, and is now attending to his usual calling. The red streaks gradually disappeared, and could hardly be traced four days after the injury.

CASE 2. -Jeremiah W-_, aged eleven, lay prostrate and unconscious, with an expression of grim terror and suffering; frothed at the mouth, and moaned piteously; flung his legs and arms about in all directions, and the by-standers expected every moment to be his last. The respiration was deep, slow, and laborious; heart palpitating; pulse weak, and very irregular ; pupils dilated and insensible. Several red streaks converged from the neck and shoulders to the middle of the sternum, and passed down, as in the former case, over the linea alba, and were lost on the pubes. From a point over the tuber ischii on either hip, narrow streaks emanated, which passed for a fow inches, like rays from a centre, in different directions, and then were lost; the resemblance as to the course these stellated rays followed, or to the figure which they formed on either hip, being so remarkably striking, that an impression of strict obedience to prevailing law could not help forcing itself on the mind of the observer. In connexion with this fact it may be stated that the patient was in the sitting posture when struck. The hair on the back of the head and neck was singed, and the peculiar singed odour above alluded to was emitted from all parts; metallic buttons showed no trace of fusion; clothes were neither burnt nor torn. Stimulants, cold to the head, blistering at the nape of the neck, mustard poultices to feet, and calhartic medicines, formed the staple part of the treatment. He rapidly recovered, became conscious in five hours, is now at work, and suffers from no symptom of nervous disorder. 'The red streaks gradually faded away, leaving behind them, where the skin was more deeply burnt, streaks of a scaly, glistening, white appearance, which in their tarn also gradually vanished, leaving behind no trace of their existence. CAsE 3.-Thomas W-C, aged forty six, (father of the boy Edward $W$-) was struck dead on the spot; he was not observed to have moved hand or foot. He, like the other two. was in the sitting posture when struck. The expression of countenance was remarkably placid; the pupils were widely dilated. The electric fluid entered at the junction of the occipital with the parietal bones, inflicting a large lacerated wound on the scalp, but not fracturing the bones of the skull. It then seemingly divided into two currents, which passed respectively downwards between soft parts and the crunium on either side of the head. That on the left side passed downwards anteriorly to the left ear, and terminated on the side of the neck, rupturing bloodvessels and soft parts, which gave rise to swelling and extravasation of blood that closely resem. bled, and might easily have been mistaken for, an extensive bruise produced by mechanical violence. The right-side current passed directly downwards to the supra clavi unlar region leaving the ear and soft parts on its way livid and swollen, and terminated, in that region, in a dark-blue, mangled-looking patch of skin, in which there were several free communiçations with the surface. The hair on the back of the head was slightly singed, that in front of the chest was singed quite close to the skin. The hair which covered the wound at the vertex of the skull was uninjured. Metallic buttons, as in the former cases, presented no appearance of fusion, and the clothes were neither torn nor burnt; but in connexion with this it is perhaps right to state that they were drenched with rain. The hat was burnt in the straw.stack, and consequently escaped ex. amination. The left side pocket of his trousers contained several lucifer-matches and a tin tobacco-box, apparently un touched. The right side-pocket contained a knife, which acquired, and still retains, strong magnetic polarity. The body was carried to a warm room. Strong cadaveric rigidity came on in fourteen hours after death. Post-mortem examination not allowed.

These cases are important, inasmuch as they tend to cast rays of light, however feeble and glimmering, on a subject as yet but imperfectly known to the scientific world, and in affording proof positive of the fact that parties betaking them. selves, during a thunderstorm, to such supposed places of protection are actually throwing themselves in the way of danger. And, again, they are interesting inasmuch as they serve to bring afresh to our recollection the v.sious effects and degrees of intensity with which this subtle agent may play its passage through the animal frame. The reader will observe the strong tendency the electric current had, in these particular cases, to unite and then run along the centre of the body, and will also notice that the general characters of tearing and burning of clothes and fusion of metallic substances about the person were not met with.

I would only add, in conclusion, that in Case 1 a state of consciousness, reason, and judgment exists, together with tem. porary suspension of the powers of voluntary motion. In Case 2 the shock given to the economy all but overwhelms the powers of life : the brain and its functions are quiescent; volition and sensation are equally lost; the lungs but sluggishly obey the call made upon them ; the heart, as if last to stop, continwes to battle for life, and by its continued though irregular action the dormant system is enabled to resume its functions. Had the shock been a shade more intense, the overpowered whole would have succumbed under it; vital action must, as in Case 3 , have been at once and completely arrested. Littleport, Cambs, June, 1864.

Australian Medicat News.-The appointment of Curator to the Australian Museum, which las been vacant since the decease of Mr. Simon Rood Pirtard, M. R.C.S. Eng. had, when the last mail left Sydney, been given to Mr. Gerard Krefft, who for some years past has discharged the practical duties of the office. It is well known that to Mr. Krefft's exertions is principally owing the splendid collec ${ }^{+}$ion of reptiles, living and preserved, at the Musenm.-Dr. Henry O. G. Smeathman, a native of England, who practised for some time in California, and was one of the correspondents of the San Francisco Bulletin, had, when the mail left, just been murdered by the Indians, in an exploring expedition be was making with Messrs. Thompson and White. It is added that the party had only one revolver between them. The Doctor always laboured under the erroneous impression that in case of trouble with Indians he could do more by Masonic signs and moral persuasion than with bullets. He fell like a brave man covering the successful retreat of his more for tunate companions 